\title{
Size constraints and flower abundance determine the number of interactions in a plant-flower visitor web
}

\author{
Martina Stang, Peter G. L. Klinkhamer and Eddy van der Meijden
}

Stang, M., Klinkhamer, P. G. L. and van der Meijden, E. 2006. Size constraints and flower abundance determine the number of interactions in a plant-flower visitor web. - Oikos 112: 111-121.

\begin{abstract}
The number of interactions with flower visitor species differs considerably among insect pollinated plants. Knowing the causes for this variation is central to the conservation of single species as well as whole plant-flower visitor communities. Species specific constraints on flower visitor numbers are seldom investigated at the community level. In this study we tested whether flower size parameters set constraints on the morphology of the potential nectar feeding visitors and thus determine the number of visitor species. We studied three possible constraints: the depth and width of tubular structures hiding the nectar (nectar holder depth and width) and the size of flower parts that visitors can land on (size of the alighting place). In addition we assess the role of flower abundance on this relationship. We hypothesized that the stronger size constraints and the smaller flower abundance, the smaller the number of visitor species will be. Our study of a Mediterranean plant-flower visitor community revealed that nectar holder depth, nectar holder width and number of flowers explained $71 \%$ of the variation in the number of visitor species. The size of the alighting place did not restrict the body length of the visitors and was not related to visitor species number. In a second step of the analyses we calculated for each plant species the potential number of visitors by determining for each insect species of the local visitor pool whether it passed the morphological limits set by the plant. These potential numbers were highly correlated with the observed numbers $\left(\mathrm{r}^{2}=0.5, \mathrm{p}<0.001\right)$. For each plant species we tested whether the observed visitors were a random selection out of these potential visitors by comparing the mean of the observed and expected proboscis length distributions. For most plant species the observed mean was not significantly different from the random means. Our findings shed light on the way plant-flower visitor networks are structured. Knowing the constraints on interaction patterns will be an important prerequisite to formulate realistic null models and understand patterns of resource partitioning as well as coevolutionary processes.
\end{abstract}

M. Stang, P. G. L. Klinkhamer and E. van der Meijden, Institute of Biology Leiden, Leiden Univ., PO Box 9516, NL-2300 RA Leiden, the Netherlands (stang@, rulsfb.leidenuniv.nl).

Plants pollinated by animals differ greatly in the number of interactions with visitor species, varying from one to more than hundred animal species (Moldenke 1975, Jordano 1987, Ellis and Ellis-Adam 1993, Waser et al. 1996). The mechanisms leading to this variation are still poorly understood (Johnson and Steiner 2000). Especially the importance of species specific constraints on this variation has seldom been investigated at the community level (Waser et al. 1996, Vazquez 2005). In order to illustrate the role of constraints, we will use traits that are thought to have an important impact on flower visitors even if they are rarely tested as a factor determining the number of visitor species (i.e. the number of interactions with flower visitor species) in a 
community context. We will start from the most basic expectation that visitors will not be able to reach the nectar if their proboscis length is shorter than the depth of the nectar holder, or if their proboscis diameter is larger than the nectar holder width. Furthermore they may have difficulties landing on a flower if their body size exceeds the size of the alighting place; for example, butterflies prefer large blossoms (Corbet 2000). We hypothesize that the stronger the size constraints, the smaller the number of visitor species will be. Within the constraints set by flower morphology, the abundance of floral rewards may also influence the number of visitor species. Optimal foraging theory predicts that if a plant species offers a greater reward it will be visited by more individuals (Fretwell and Lucas 1970, Pleasants 1981, Dreisig 1995) and, as a consequence, also by a higher number of visitor species (Possingham 1992).

Only a few studies directly examined the relationship between size parameters and the number of visitor species. They do not show a clear picture. Herrera (1996) found that within the 14 plant species he studied plants with a flower tube depth shorter than $10 \mathrm{~mm}$ were visited by a significantly larger number of visitor species than plants with a flower tube deeper than $20 \mathrm{~mm}$. Agosta and Janzen (2005) analyzed data provided by Haber and Frankie (1989) and showed that there is a significant association between flower tube depth of hawkmoth flowers and visitor richness of hawkmoths. Yet, there was no relationship found between flower tube depth of Asteraceae species and visitor numbers (Torres and Galetto 2002) or flower depth of Echium species and the number of visiting bee species (Dupont and Skov 2004). Likewise, an analysis of data provided by Harder (1985) and Corbet (2000a) revealed no significant relationship between flower tube depth and number of bumblebee or butterfly species, respectively. Conversely, it seems well established that there is a positive relationship between the total number of visitor species found in a community at a given time and the floral abundance of all plant species (Heithaus 1974, Moldenke 1975, Steffan-Dewenter and Tscharntke 1997, Potts et al. 2003) while nectar volume, nectar sugar composition or energy content of pollen were unrelated with the number of visitor species (Petanidou and Vokou 1990, Petanidou and Ellis 1996, Torres and Galetto 2002, Potts et al. 2003). Nevertheless, plant species based comparisons between resource parameters and visitor species numbers at the community level are rare or even missing.

Plant-flower visitor communities can be studied in the manner of food webs or networks (Memmott 1999, Dicks et al. 2002, Olesen and Jordano 2002). An important parameter that might influence the stability of a food web is the connectance, i.e. the percentage of all possible interactions within a community that are actually observed. The number of all possible interactions (the size of the plant-flower visitor network) is calculated by multiplying the number of plant species with the number of flower visitor species. Yet, the number of interactions that is actually expected might be strongly reduced by morphological constraints and thus depends on the species composition (Jordano 1987, Warren 1994, Jordano et al. 2003). Morphological traits of the plants act as filters allowing only certain visitors the access to nectar and/or pollen. Constraints are usually ignored in flower visitation web analyses because of missing morphological information about whole plant-flower visitor communities (Olesen and Jordano 2002, Vazquez 2005). Yet, with this information we will better understand the frequency distribution of specialization levels within flower visitation webs and thus community wide patterns of linkage levels (Ollerton and Cranmer 2002) and connectance (Olesen and Jordano 2002). We also think that constraints on interaction patterns will be an important prerequisite to formulate realistic null models to understand interaction patterns.

In this study we examine whether the number of nectar feeding visitor species is related to flower size parameters and flower abundance in a local plantflower visitor community. The restriction to nectar feeding visitors is essential given the traits we want to investigate. What is more, nectar producing flowers are normally better adapted to direct nectar feeding visitors into an optimal position for pollination than visitors searching for pollen (Westerkamp 1987). We chose a Mediterranean plant-flower visitor community because of the potentially high species diversity of flower visitors (Petanidou and Ellis 1993). We based our analysis on a complete flower visitation web, i.e. we included all insect orders observed on the plant species. The total number of open flowers in the observation plots was used as a measurement of flower abundance. We decided to use equal observation periods for all plant species because differences in observation effort can alter the number of observed visitors independent of size constraints and flower abundance (Ollerton and Cranmer 2002).

In order to test if a possible association between morphology and visitor numbers is based on a causal relationship we analyzed whether flower morphology constrains the morphology of nectar foraging visitors. We realize that visitors sometimes may overcome morphological limitations such as nectar robbers piercing corollas, small insects able to enter the nectar holder tube with parts of their body and hovering hawkmoths or beeflies that do not need to alight on a flower to feed nectar. However, if the traits chosen act as important constraints for the majority of the visitor species, we expect that the potential number of visitor species on a plant species is positively correlated with the actually observed number of visitor species on a plant species. We define the potential number of visitors of a plant species as those visitors that pass the morphological thresholds within the total sample of flower visitors observed in the 
flower visitation web. To test if our assumption holds that the observed visitors of a plant species came from the whole morphological spectrum of the potential visitors of that plant species, we performed Monte Carlo simulation tests and examined whether the observed visitors are a random draw out of the potential visitors. Specifically we want to test the following hypotheses based on null models using the frequency distribution of visitor traits in the local visitor community:

1) The number of flower visitor species decreases with increasing size constraints and decreasing flower abundance.

2) Flower morphology sets thresholds on the morphology of nectar foraging visitors.

3) If so, the potential number of visitor species based on these thresholds is positively correlated with the observed number of visitor species.

4) The observed visitors on a plant species are a random draw out of the whole potential morphological range of visitors of that plant species.

\section{Material and methods}

\section{Study site and selection of plants}

The study was conducted in a Mediterranean vegetation mosaic in the southeast of Spain $(15 \mathrm{~km}$ to the west of Alicante, $\left.38^{\circ} 22^{\prime} \mathrm{N}, \quad 0^{\circ} 38^{\prime} \mathrm{W}\right)$. The vegetation was a combination of garigue, almond tree groves and roadside vegetation. We selected 10 observation plots of $200 \mathrm{~m}^{2}$ within a $25 \mathrm{~m}$ wide strip of a road segment of $3 \mathrm{~km}$ length. In each of the plots we selected all nectar producing plant species with more than five flowering individuals in that plot. Observations were made during 6 weeks in March and April 2003. The selection resulted in 25 plant species distributed over 11 plant families, representing all main structural blossom types (Faegri and van der Pijl 1979).

\section{Flower size parameters}

From 5 to 10 individuals of each plant species we selected flowers which were in the male or hermaphrodite phase. We measured depth and width of the nectar holder tube and size of the alighting place to the nearest $0.10 \mathrm{~mm}$ with a digital calliper under a dissecting microscope. Because tubes were formed by hairs, the receptacle, the calyx, the corolla, filaments or a combination of organs, we use the term nectar holder tube instead of the more widespread but in our case incorrect term corolla tube. In some species a nectar holder tube was absent and nectar glands were openly accessible. In this case nectar holder depth was scored as $0 \mathrm{~mm}$. The depth of nectar holder was measured from the base to the top of the nectar holder. The top is the entrance of the nectar holder at the point where only a proboscis can enter, and is normally smaller than $1.0 \mathrm{~mm}$. Nectar standing crop of the investigated species was generally small and the observed height of nectar levels in the field was low. This seems typical for plant species of Mediterranean dry habitats (Petanidou and Smets 1995). Only in Matthiola fruticulosa (Loefl. ex L.) Maire we observed nectar levels of 1 to $2 \mathrm{~mm}$ above the nectaries so that a visitor with a shorter proboscis than the measured nectar holder depth can reach the nectar. This species opens its flowers late in the afternoon and seems to be adapted to night flying visitors. In the Asteraceae we measured the depth of the upper wider part of the corolla, which roughly begins where the stamens insert and ends where the corolla flares out (Corbet 2000a). At the bottom of the wider part you can sometimes find traces of nectar. None of the observed visitor species was physically able to enter the narrow part of the tube. The width of the nectar holder was measured at the middle of the tube after a cross section. If nectar was openly presented the diameter of the nectar glands was used. Almost all observed visitors landed on the flowers to get access to nectar (the observed exceptions were some large beeflies). The alighting place was measured as the distance between the entrance of the nectar holder tube and the functional border of the pollination unit or blossom (Faegri and van der Pijl 1979).

\section{Flower abundance}

We estimated the total number of open flowers in the 10 observation plots by multiplying the mean number of open flowers per blossom with the mean number of blossoms per individual and the total number of individuals. The total number of flowering individuals was counted once in the 10 observation plots during the observation period of a species. The number of flowering blossoms per individual and the number of open flowers per blossom were estimated by counting these parameters on 10 to 20 individuals within 3 plots of $10 \times 10 \mathrm{~m}$.

\section{Flower visitor censuses}

Each plant species was observed four times for $15 \mathrm{~min}$. Within each observation period we changed about every minute the observed individuals of a plant species within a plot. The four observation periods were evenly distributed between 10 am to $6 \mathrm{pm}$, including only day flying visitor species. Species that present their food only during a part of the day were observed only during that period (e.g. Sonchus tenerrimus L., Reichardia tingitana 
(L.) Roth., Linum suffruticosum L., Matthiola fruticulosa (Loefl. ex L.) Maire). We randomly spread the four observation periods over different observation plots and sampling days within a 15 day period for each species. We recorded if a visitor collected nectar, pollen or both, and counted the number of visiting individuals per visitor species. Only those visitors were included that were visiting a minimum of three flowers in sequence or stayed more than three seconds in a flower to exclude accidental visitors. We observed 1206 individuals of which 887 fed on nectar or nectar and pollen. The majority of the nectar feeding individuals in our study picked up pollen and touched stigmas during their visits. Nevertheless, pollination efficiency of the different species and even individuals may differ considerably.

\section{Visitor traits}

The insect species were, if possible, identified to species level or otherwise to family or genus level and then assigned to "morphospecies" categories. We are confident that these morphospecies represent in most cases single taxonomic species. One to 11 specimens of each species were collected. All voucher specimens are kept by the first author. Size parameters were measured from in total 278 specimens immediately after killing to ensure the flexibility of the mouthparts (hereafter called proboscis). We used a digital calliper and measured the proboscis and body dimensions to the nearest $0.10 \mathrm{~mm}$ under a dissecting microscope. For the Hymenoptera the length of the proboscis was measured as the length of the fully extended prementum and glossa. For long-tongued bees it reflects the maximum depth to which an individual can probe, the normal extension of the proboscis during nectar feeding (functional length) is about $70 \%$ of the maximum length (Harder 1982). For short-tongued bees the length of prementum and glossa represents both the functional and maximum length of the mouthparts (Harder 1983). The proboscis of the Diptera (labium) was measured after slightly pulling it out of the head because it often has a contractile basal part (Gilbert 1981). The proboscis of the Lepidoptera was unrolled before measuring. Within the Coleoptera we used the length of the mandibles. The proboscis diameter was defined as the broadest part within the first millimetre of the tip of the proboscis after preparation for length measurements. Before measuring the body length insects were straightened and the length of the body parts (head, thorax, abdomen) were measured according to common determination literature instructions. Body length was functionally defined as the length of head, thorax and femur because the abdomen plays no role in the landing ability of the flower visitors. Total body length (head, thorax and abdomen) and functional body length were highly correlated $(\mathrm{r}=0.95, \mathrm{p}<0.001$, $\mathrm{n}=111)$.

\section{Data analysis}

Statistical analysis was performed using SPSS 11.0. A Kolmogorov-Smirnov test was used to test if the variables were normally distributed. Nectar holder width, total number of flowers, observed number of visitor species, potential number of visitor species and the ratio of observed to potential visitor species were $\log$ transformed to achieve normality. Relationships between flower parameters were tested with Pearson correlations. Correlations between size parameters of insects were tested with Spearman rank correlations because transformations did not result in normally distributed variables. We tested the association between flower parameters and number of visitor species with multiple least square regression and backward selection of variables.

We analysed which of the three size parameters restricted the observed visitors and used those that did so to determine the potential number of visitor species. We tested the minimum nectar holder depth, the maximum nectar holder width and the maximum alighting place length (Appendix 1). Minimum and maximum values better reflect the actual limits to potential flower-visitor interactions than mean values. Those insect species of the local visitor pool were treated as potential visitors of a plant species that met with their morphology the morphology of the flowers: a proboscis as long as or longer than the nectar holder depth and a proboscis as small as or smaller than the nectar holder width (Results). We tested the relationship between potential and observed number of visitors with linear regressions. The difference in the explained variance of the two regression models (the potential visitors based on nectar holder depth alone and that based on a combination of nectar holder depth and width) was tested with a paired samples t-test.

In order to estimate if the observed visitors that met the size criteria are a random selection out of the potential visitors we performed Monte Carlo simulation tests (Hood 2005). We chose the mean proboscis length as a test variable and compared the observed mean with the means of 1000 random draws (without replacement) from the potential visitors. The observed number of visitors on a plant species was used as the sample size. We considered the observed mean to be significantly different from the random means if it was smaller than the 25 th smallest or larger than the 25th largest random mean. This difference statistic is provided by the programme poptools (Hood 2005).

One drawback of equal and relatively short observation periods is that the ratio of observed to potential 
visitors may not be constant but could decrease with weaker size constraints and thus an increasing potential number of visitors, likely because of the increasing time needed to encounter all potential species. To asses if the ratio of observed to potential visitors declined with increasing potential number of visitors we adopted the approach of Klinkhamer et al. (1990). The ratio of observed to potential visitors has to be calculated by dividing the potential by the observed number of visitors so that the potential number of visitors would be included in the independent and the dependent variable, which may result in an artificial correlation. To avoid this problem we tested with an F-test if the regression coefficient of the log transformed numbers of observed versus potential visitors was significantly smaller than 1.

\section{Results}

\section{Flower traits}

Among the 25 plant species nectar holder depths varied between 0 to $10 \mathrm{~mm}$ and nectar holder widths between 0.1 to more than $2 \mathrm{~mm}$ (Appendix 1). Depth and width of the nectar holders were not correlated $(\mathrm{r}=-0.06, \mathrm{p}=$ $0.79, \mathrm{n}=25)$. The size of the alighting place varied between 2.9 and $15.7 \mathrm{~mm}$. It was neither correlated with nectar holder depth $(\mathrm{r}=0.07, \mathrm{p}=0.75, \mathrm{n}=25)$ nor with nectar holder width $(\mathrm{r}=-0.01, \mathrm{p}=0.96, \mathrm{n}=25)$. The number of flowers per plant species varied almost 900 fold with a minimum of about 400 flowers (Erodium macaloides (L.) L'Her.) and a maximum of almost 330000 flowers (Helichrysum stoechas (L.) Moench). The deeper the nectar holder the smaller the number of open flowers that were available for the visitors $(\mathrm{r}=$ $-0.51, \mathrm{p}=0.01, \mathrm{n}=25)$. There was no significant relationship between nectar holder width and number of flowers $(\mathrm{r}=0.14, \mathrm{p}=0.493, \mathrm{n}=25)$.

\section{Visitor traits}

The 111 nectar feeding visitor species covered five orders. The Hymenopterans were the species-richest group with 55 species (42 bees, 9 wasps and 5 ants), followed by the Dipterans with 35 species (17 "muscoid" flies, 7 hoverflies, 5 bee flies and 6 other), the Lepidoptera with 9 species ( 7 butterflies and 2 moths), the Coleopterans with 7 species and the Heteropterans with 5 species. With 662 observed individuals the Hymenoptera were the most common visitors, even if the 298 individuals of Apis mellifera were excluded. The distributions of proboscis length $(0.1-14.0 \mathrm{~mm})$ and diameter $(0.1-0.6 \mathrm{~mm})$ were positively skewed with a mean of $3.45 \mathrm{~mm}$ and $0.23 \mathrm{~mm}$, respectively. Both parameters were not significantly correlated $\left(\mathrm{r}_{\mathrm{s}}=-0.13, \mathrm{p}=0.162, \mathrm{n}=111\right)$ but the distribution was clearly triangular with a linearly decreasing upper ceiling (Fig. 1a). Species with a short proboscis show a large variation of proboscis diameters. With increasing proboscis length mean proboscis diameter as well as variation in diameters decrease. Long proboscises are mostly thin. The number of individuals per insect species increased with increasing proboscis length $\left(\mathrm{r}_{\mathrm{s}}=\right.$ $0.29, \mathrm{p}=0.002, \mathrm{n}=111)$. Functional body length $(1.5-$ $11.2 \mathrm{~mm}$ ) was normally distributed and positively correlated with proboscis length $\left(\mathrm{r}_{\mathrm{s}}=0.84, \mathrm{p}<0.001\right.$, $\mathrm{n}=111$ ), again, with an obviously triangular distribution (Fig. 1b). Species with a short proboscis had small or large bodies, long proboscises were only found in species with large bodies.

\section{Flower traits and observed number of visitor species}

The number of visitor species on each plant species ranged from 1 to 29 insect species (mean of 9.24, median of 7.0, Appendix 1). The number of visitor species decreased with increasing nectar holder depth $\left(r^{2}=0.36, p=0.002, n=25\right.$, Fig. 2a) and decreasing nectar holder width $\left(\mathrm{r}^{2}=0.25, \mathrm{p}=0.011, \mathrm{n}=25\right.$, Fig. 2b), while there was no significant correlation with the size if the alighting place $\left(r^{2}=0.004\right.$,
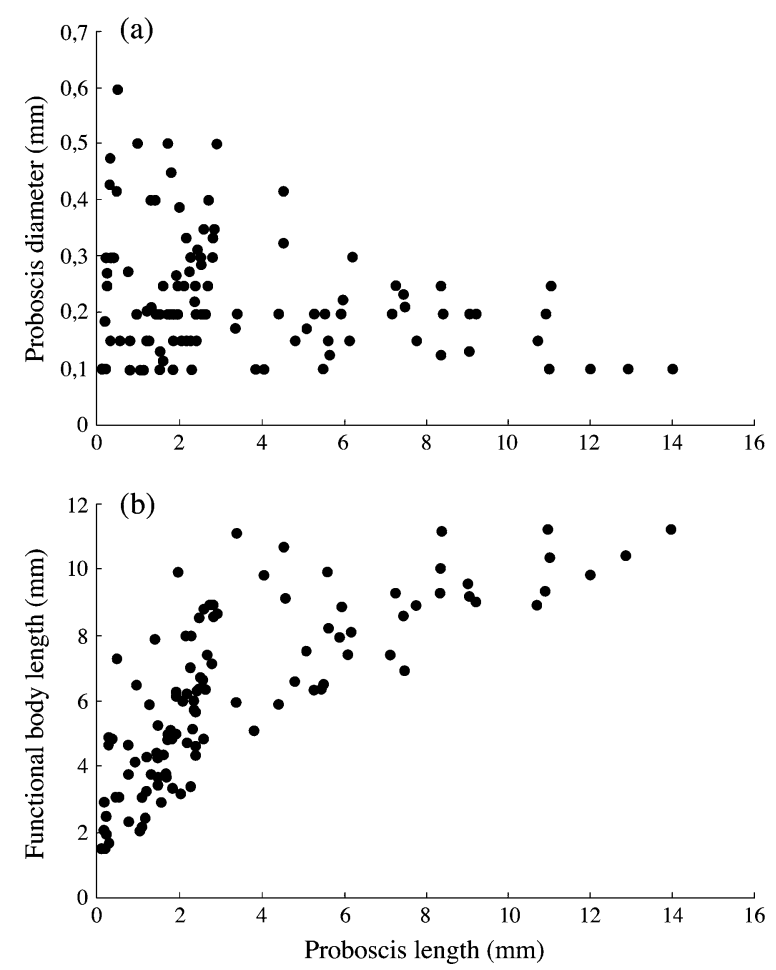

Fig. 1. Relationship between proboscis length and (a) proboscis diameter and (b) functional body length (the length of head, thorax and femur). Each dot represents one insect species. 

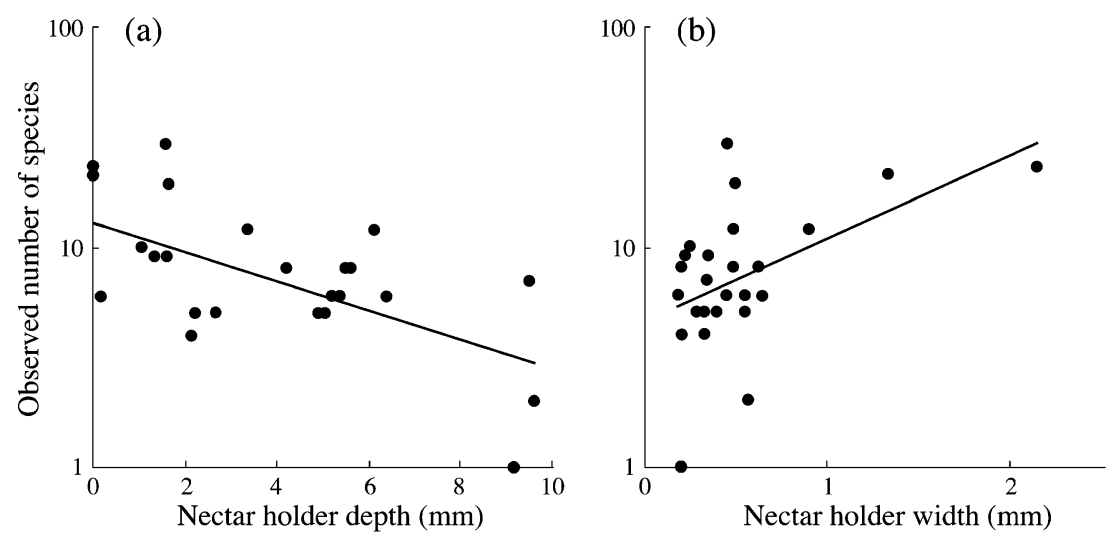

Fig. 2. Relationship between flower traits and observed number of visitor species. (a) nectar holder depth, (b) nectar holder width, (c) length of the alighting place, (d) total number of flowers. Each dot represents one plant species. Y-axes in all four graphs are on a logarithmical scale. Nectar holder width is log transformed before statistical analysis to achieve normality; values in the graph are given without transformation.
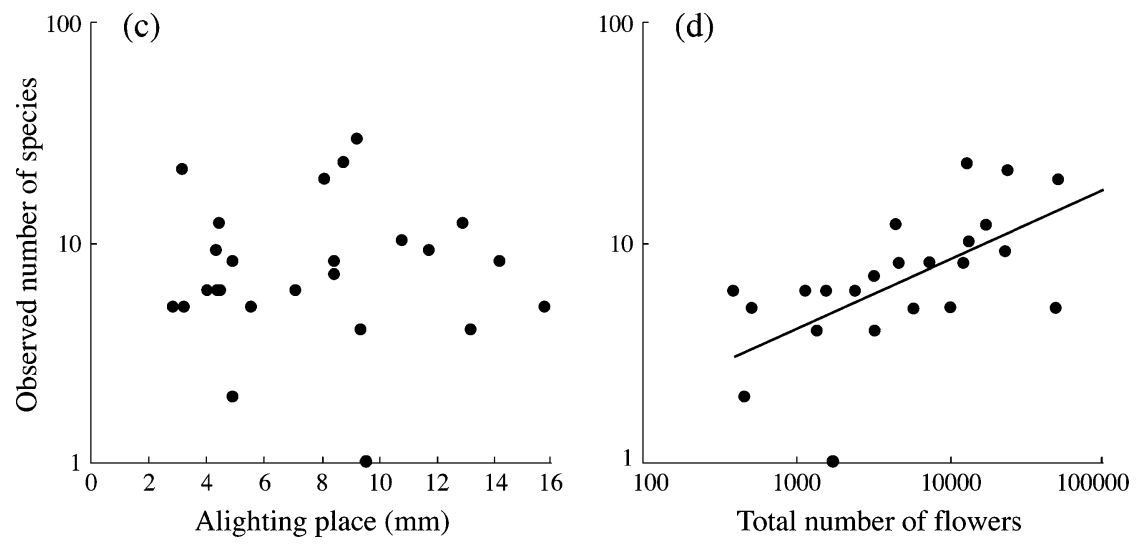

$\mathrm{p}=0.984, \mathrm{n}=25$, Fig. 2c). Species with a large total number of open flowers were visited by more visitor species $\left(r^{2}=0.45, p<0.001, n=25\right.$, Fig. $\left.2 d\right)$. The simple regressions are still significant after a Bonferroni correction for multiple single comparisons has been applied (i.e. critical p-value $<0.0125$ ). A multiple regression analysis shows that nectar holder depth, nectar holder width and flower abundance explained $71 \%$ of the variation in the observed number of visitor species $\left(\mathrm{r}^{2}=0.71, \mathrm{p}<0.001, \mathrm{n}=25\right.$, Table 1$)$. The three variables contribute significantly and almost equally to the explained variation.

Table 1. Multiple regression (method backward selection of variables) with $\log$ number of observed visitor species as the dependent variable and nectar holder depth, nectar holder width, alighting place length and total number of flowers as independent variables. Alighting place length was excluded from the model: $(\mathrm{t}=1.53$ and $\mathrm{p}=0.141)$. The explained variance of the presented model is $71 \%\left(\mathrm{r}^{2}=0.71, \mathrm{p}<0.001, \mathrm{n}=25\right)$.

\begin{tabular}{lcrc}
\hline $\begin{array}{l}\text { Independent } \\
\text { variables }\end{array}$ & $\begin{array}{c}\text { Standardized } \\
\text { coefficient (Beta) }\end{array}$ & $\mathrm{t}$ & $\mathrm{p}$ \\
\hline (constant) & & 1.587 & 0.127 \\
nectar holder depth & -0.359 & -2.643 & 0.015 \\
log nectar holder & 0.418 & 3.532 & 0.002 \\
$\quad$ width & 0.429 & 3.134 & 0.005 \\
log total number & & & \\
$\quad$ flowers & & & \\
\hline
\end{tabular}

\section{Size constraints and potential number of visitor species}

Only $7.5 \%$ of the 887 observed insect individuals were insects with a proboscis shorter than the nectar holder depth and $3.5 \%$ were insects with a proboscis larger than the nectar holder width (together 8.7\%). Nectar holder depth exceeded proboscis length by maximally $1.5 \mathrm{~mm}$ and proboscis diameter exceeded nectar holder width by maximally $0.1 \mathrm{~mm}$. The observed minimum proboscis length of the insect species visiting a plant species was strongly correlated with nectar holder depth $\left(\right.$ length $_{\min }=$ $0.95 \times$ depth $\left.-0.15, \mathrm{r}^{2}=0.89, \mathrm{p}<0.001, \mathrm{n}=25\right)$. The alighting place did not restrict body length of the visitors. Almost 38\% had a longer functional body length than the length of the alighting place.

Based on the previous results we calculated the potential number of visitors, firstly by using the nectar holder depth alone and secondly by the combination of the nectar holder depth and width (Appendix 1). In both cases a significant positive correlation with the observed number of visitors was found $\left(\mathrm{r}^{2}=0.39, \mathrm{p}=0.001, \mathrm{n}=25\right.$ and $\mathrm{r}^{2}=0.50, \mathrm{p}<0.001, \mathrm{n}=25$, respectively, Fig. 3$)$. The explained variance was higher in the latter one, although the difference was not significant $(\mathrm{t}=1.787, \mathrm{p}=0.087)$. In a multiple regression analysis with potential number of visitors (based on nectar holder depth and width) and 


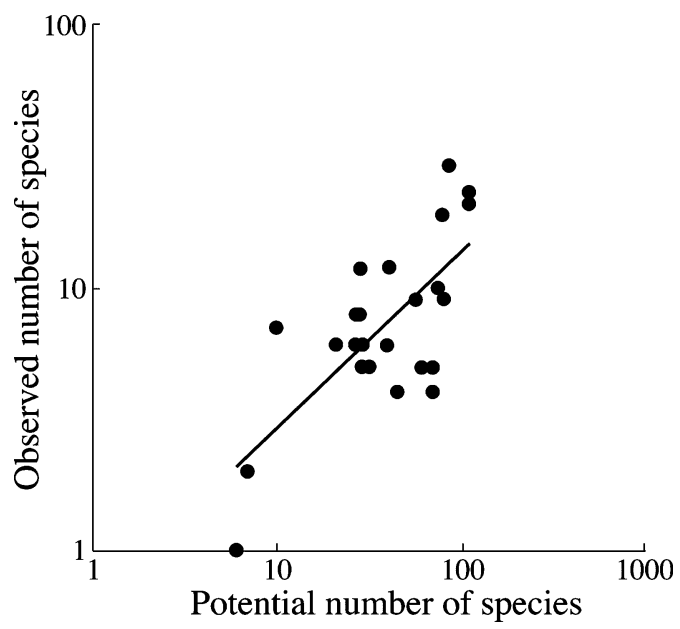

Fig. 3. Relationship between potential and observed number of visitor species. Potential number of species was determined based on the nectar holder depth and width constraint. Each dot represents one plant species. Both axes are on a logarithmical scale to achieve normality.

flower abundance as independent variables, flower abundance $(\mathrm{p}=0.046)$ increased the explained variance in observed number of visitors even further $\left(\mathrm{r}^{2}=0.59\right.$, $\mathrm{p}<0.001, \mathrm{n}=25$ ).

The potential number of visitors (based on nectar holder depth and width) decreased exponentially with increasing nectar holder depth $\left(\mathrm{r}^{2}=0.88, \mathrm{p}<0.001, \mathrm{n}=\right.$ $25)$. Nectar holder width has the largest influence on the number of potential visitors for flowers with short nectar holder tubes (Appendix 1). For most of the plant species $(72 \%)$ the proboscis lengths of the observed visitors are random selections out of the proboscis lengths of the potential visitors (Fig. 4).

\section{Ratio of observed to potential visitor species}

On average about a quarter of the potential visitors were observed on a plant species $(0.23 \pm 0.14)$. This ratio increased slightly but significantly with increasing nectar holder depth and decreasing nectar holder width $\left(\mathrm{r}^{2}=\right.$ $0.384, \mathrm{p}=0.005, \mathrm{n}=25)$, i.e. the stronger the size constraints, the higher the ratio of observed to potential visitors. The regression coefficient of the log transformed number of observed versus potential visitors was significantly smaller than $1(\mathrm{~F}=5.846, \mathrm{p}=0.023)$, indicating that the ratio of observed to potential visitors decreased significantly with increasing potential number of visitors. The ratio was not correlated with flower abundance $\left(\mathrm{r}^{2}=0.00, \mathrm{p}=0.97, \mathrm{n}=25\right)$, yet, a multiple regression of flower abundance and potential number of visitor species against this ratio revealed an almost significant contribution of flower abundance $(\mathrm{t}=2.08$, $\mathrm{p}=0.05, \mathrm{n}=25)$.

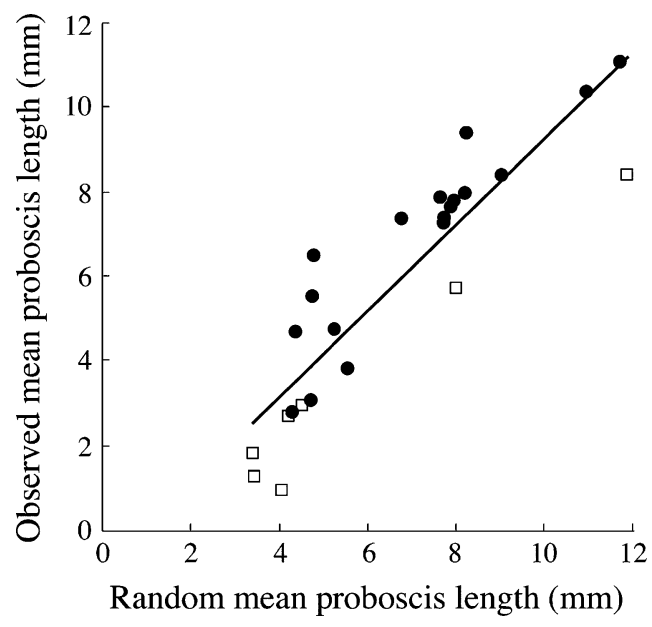

Fig. 4. Observed versus random mean proboscis lengths. The observed means that differed significantly from the random means are indicated with an open square. Both variables are significantly correlated $\left(\mathrm{r}^{2}=0.81, \mathrm{p}<0.001, \mathrm{n}=25\right)$. Each $\mathrm{dot}$ represents one plant species. The plant species that differ significantly from a random draw are Anacyclus valentinus, Erodium malacoides, Euphorbia serrata, Euphorbia terracina, Helichrysum stoechas, Matthiola fruticulosa and Sideritis leucantha.

The ratio of all 231 actually observed plant speciesinsect species interactions to all 2775 possible interactions was 0.12 (i.e. the connectance of this plant-flower visitor community). Due to the size constraints, the actually expected interactions were reduced by $57 \%$, i.e. from 2775 to 1195 . This means that more than half of the not observed interactions of the whole community can be explained by size constraints.

\section{Discussion}

\section{Flower parameters and number of visitor species}

Our results clearly show that most of the variation in the number of nectar foraging visitor species can be explained on basis of two simple morphological constraints and flower abundance. The number of visitor species significantly decreased with increasing nectar holder depth and decreasing nectar holder width. The size of the alighting place was unrelated to the number of visitor species. This is the first report of an association between nectar holder sizes and the number of visitor species in a community-based study. Most other studies analyzing size parameters have been based on broader geographical areas or have included only one plant family or one visitor group, and they have found only in part an association (Haber and Frankie 1989, Herrera 1996, Torres and Galetto 2002, Dupont and Skov 2004). Although the range of nectar holders in the community studied here was only one third to one half of the range 
analyzed in other studies (Herrera 1996, Torres and Galetto 2002), the relationship between nectar holder morphology and species number was still strong. The observed strength of the relationship could be partly caused by the fact that the analysis was, contrary to other studies (Torres and Galetto 2002, Dupont and Skov 2004), restricted to nectar foraging visitors. That the number of flowers per plant species was positively related to the number of nectar feeding insect species is in accordance with predictions of optimal foraging theory (Possingham 1992) as well as with other empirical data (Heithaus 1974, Moldenke 1975, Potts et al. 2003). Although each of the three flower parameters alone was significantly correlated with the number of visitor species, only the combination explained the high amount of variation in species numbers and stresses the importance to include all of them in a study which tries to explain the level of ecological specialization to flower visitors.

\section{Size constraints as a determinant of the number of visitor species}

Although rarely, we sometimes observed insect species that seem to be able to overcome size constraints because they were visiting flowers that had longer and narrower nectar holders than their proboscis lengths and diameters would let expect. These observations may be explained by a number of reasons. Nectar can accumulate so that nectar levels can be considerably higher than the base of the nectar holder. Additionally, flowers with very short nectar holder tubes were sometimes visited by small insects with head diameters that are smaller than that of the nectar holder (pers. obs.). Species of the Brassicaceae and Fabaceae have often flexible nectar holder widths because the petals forming the nectar holder tube are not fused. Given these exceptions, the percentage of visitor species that fell outside the limits set by the nectar holder was with less than $9 \%$ remarkably low. Conversely, the percentage of visitors with a functional body length that exceeds the potential size limits of the alighting place was with almost $38 \%$ high. This is mainly a result of the flexibility of insect behavior. Sometimes visitors used the whole diameter of a flower or adjacent flowers to sit on, as well as parts of the calyx of sideward orientated flowers with a lower lip as alighting place. Some of the visitors (such as beeflies) hover in front of a flower.

As expected, potential and observed number of visitor species was positively related. The relationship was stronger if the potential visitors were determined with both nectar holder size constraints, although the increase in explained variance was marginally not significant. Visitors with short proboscises had a much higher variance of proboscis widths than visitors with a long proboscis (Fig. 1a). Given this distribution, especially flowers with short nectar holder tubes can restrict the number of visitors by narrowing down nectar holder width. This explains why nectar holder width had the largest influence in restricting the number of potential visitors for flowers with short nectar holder tubes.

For about three quarter of the plant species, the mean proboscis length of the observed visitors could not be distinguished from a random selection out of the potential visitors. For all cases that differ significantly from a random draw, the observed mean proboscis length was smaller than the random mean, indicating a better matching between nectar holder depth and proboscis length of the visitors than expected by chance. Five of the seven plant species that differ significantly from a random draw had dishshaped blossoms with easily accessible nectar. It is very likely that these plant species have a low nectar production per flower. In Mediterranean shrublands nectar holder depth is positively correlated with nectar volume and negatively with nectar concentration (Petanidou and Smets 1995). Flower visitors with a long proboscis often need more energy because of their larger body sizes (proboscis length and body size is positively correlated). For them it is not profitable to exploit flowers with a low nectar production if these flowers are scarce. Visitors with a long proboscis may have also more difficulties to exploit highly concentrated nectar (Gilbert and Jervis 1998).

\section{Ratio of observed to potential visitors}

On average $23 \%$ of the potential visitors were observed on a plant species. This percentage was larger for plant species with stronger size constraints and thus a smaller potential number of visitor species. The decreasing ratio of observed to potential visitors might be an artefact caused by the sampling procedure. Observed species richness increases with increasing sampling effort (Ollerton and Cranmer 2002), and with increasing potential number of species the time needed to observe all potential visitors will increase. This relationship was very likely intensified by flower abundance (even if the relationship with the ratio was only marginally significant) as well as by the increasing observed number of individuals per insect species with increasing proboscis length. As a result, the variation in the observed number of species was partly masked, and we expect that the difference in the number of flower visitor species (i.e. the level of ecological specialization to flower visitors) will be even larger when based on longer observation intervals. 


\section{Implications for the analysis of plant-flower visitor webs}

Our findings have important implications for community based studies analysing the structure of whole plantpollinator webs or interaction networks (Memmott 1999, Dicks et al. 2002, Memmott and Waser 2002, Olesen and Jordano 2002, Vazquez and Aizen 2003). In network analysis the number of possible interactions is defined as the product of the number of plant and animal species. Usually only a small number of these possible interactions are actually observed. The important question is whether the ones that are not observed are drawn by chance or for some reason cannot occur. In the latter case they are referred to as forbidden interactions or links (Jordano et al. 2003, Vazquez 2005). Jordano (1987) suggested that an increasing corolla length would cause an exponential decrease in the fraction of potentially interacting mutualists in a plant-pollinator network. We were able to show this exponential decrease based on a local visitor species pool. As a result, size constraints explain in our system about half of the not observed interactions and only within the allowed insect species the visitors were a random draw. The restriction of an analysis to the frequency of visitors as the most parsimonious explanation for the number of insect species per plant species as proposed by Vazquez (2005) will obscure the underlying mechanism of this relationship. We have shown that the number of insect individuals increased with increasing proboscis length, indicating that constraints are very likely the underlying cause of the association between the frequency of visitors and the number of plant species visited.

Connectance and the mean number of interactions per plant species within a community differs considerably (Olesen and Jordano 2002, Ollerton and Cranmer 2002). On basis of our results we suppose that this difference is caused by a shift in the morphological character distribution of the plant and visitor species. However, flowers are visited by nectar and pollen visitors. Following up studies should thus include pollen foraging visitors as well as the traits that will restrict them, e.g. whether pollen is free accessibility or hidden in flower structures. Phenological mismatching between flowers and visitors (Jordano et al. 2003) were not likely for our dataset because of the restricted observation time of 6 weeks.

As far as we know, our study is the first that documented morphological constraints and their significance for the variation in the number of flower visitors in a local plant-flower visitor web including a broad range of plant families and insect orders. It is also the first that based the potential number of flower visitors on size constraints. Size constraints and floral abundance will provide an important basis to under- stand interaction patterns in flower visitation webs. Knowing the constraints on these patterns will be an important prerequisite to formulate realistic null models (Gotelli and Graves 1996, Vazquez and Aizen 2003, Vazquez 2005) and understand resource partitioning and compartmentalization in studies that include the visitation frequency of the flower visitors (Dicks et al. 2002). It may help to predict the susceptibility of flower visitation webs to disturbance and thus facilitate the conservation of species diversity (Corbet 2000b, Memmott et al. 2004). Interactions patterns will on their part influence the co-evolution of flowers and their pollinators (Jordano 1987, Jordano et al. 2003).

Acknowledgements - We want to thank Kirsten Kaptein and Vera Geluk (Univ. of Leiden, the Netherlands) for their assistance in the field and fruitful discussions during fieldwork, Benito Crespo and Ana Juan (Univ. of Alicante, Spain) helping to find a study area and to determine the plant species, Maria Angeles Marcos Garcia and Celeste Bañon (Univ. of Alicante, Spain) for determining the Syrphid flies, and Maria Angeles Marcos Garcia to get permissions to collect plant and insect species. We also thank Heather Kirk, Sonja Esch and Angela Schulz for their comments on an earlier version of this paper.

\section{References}

Agosta, S. J. and Janzen, D. H. 2005. Body size distributions of large Costa Rican dry forest moths and the underlying relationship between plant and pollinator morphology. - Oikos 108: 183-193.

Corbet, S. A. 2000a. Butterfly nectaring flowers: butterfly morphology and flower form. - Entomol. Exp. Appl 96: 289-298.

Corbet, S. A. 2000b. Conserving compartments in pollination webs. - Conserv. Biol. 14: 1229-1231.

Dicks, L. V., Corbet, S. A. and Pywell, R. F. 2002. Compartmentalization in plant-insect flower visitor webs. - J. Anim. Ecol. 71: 32-43.

Dreisig, H. 1995. Ideal free distributions of nectar foraging bumblebees. - Oikos 72: 161-172.

Dupont, Y. L. and Skov, C. 2004. Influence of geographical distribution and floral traits on species richness of bees (Hymenoptera: Apoidea) visiting Echium species (Boraginaceae) of the Canary Islands. - Int. J. Plant Sci. 165: $377-$ 386.

Ellis, W. N. and Ellis-Adam, A. C. 1993. To make a meadow it takes a clover and a bee - the entomophilous flora of $\mathrm{Nw}$ Europe and its insects. - Bijdragen Tot De Dierkunde 63: $193-220$

Faegri, K. and van der Pijl, L. 1979. The principles of pollination ecology. - Pergamon Press.

Fretwell, S. D. and Lucas, H. J. J. 1970. On territorial behaviour and other factors influencing habitat distribution in birds. - Acta Biotheor. 19: 16-36.

Gilbert, F. S. 1981. Foraging ecology of hover flies - morphology of the mouthparts in relation to feeding on nectar and pollen in some common urban species. - Ecol. Entomol. 6: $245-262$.

Gilbert, F. and Jervis, M. 1998. Functional, evolutionary and ecological aspects of feeding-related mouthpart specializations in parasitoid flies. - Biol. J. Linn. Soc. 63: 495-535.

Gotelli, N. J. and Graves, G. R. 1996. Null models in ecology. - Smithsonian Institution Press. 
Haber, W. A. and Frankie, G. W. 1989. A tropical hawkmoth community: Costa Rican dry forest Sphingidae. - Biotropica 21: $155-172$.

Harder, L. D. 1982. Measurement and estimation of functional proboscis length in bumblebees (Hymenoptera, Apidae). - Can. J. Zool. Rev. Can. Zool. 60: 1073-1079.

Harder, L. D. 1983. Functional differences of the proboscides of short-tongued and long-tongued bees (Hymenoptera, Apoidea). - Can. J. Zool.-Rev. Can. Zool. 61: 15801586.

Harder, L. D. 1985. Morphology as a predictor of flower choice by bumblebees. - Ecology 66: 198-210.

Heithaus, E. R. 1974. The role of plant-pollinator interactions in determining community structure. - Ann. Miss. Bot. Gard. 61: 675-691.

Herrera, C. M. 1996. Floral traits and plant adaptation to insect pollinators: a devils's advocate approach. - In: Lloyd, D. G. and Barrett, S. C. H. (eds), Floral biology. Studies of floral evolution in animal-pollinated plants. Chapman and Hall, pp. $65-87$.

Hood, G. M. 2005. Poptools. - Available on the internet. URL http://www.cse.csiro.au/poptools.

Johnson, S. D. and Steiner, K. E. 2000. Generalization versus specialization in plant pollination systems. - Trends Ecol. Evol. 15: 140-143.

Jordano, P. 1987. Patterns of mutualistic interactions in pollination and seed dispersal - connectance, dependence asymmetries, and coevolution. - Am. Nat. 129: 657677.

Jordano, P., Bascompte, J. and Olesen, J. M. 2003. Invariant properties in coevolutionary networks of plant-animal interactions. - Ecol. Lett. 6: 69-81.

Klinkhamer, P. G. L., Dejong, T. J. and Meelis, E. 1990. How to test for proportionality in the reproductive effort of plants. - Am. Nat. 135: 291-300.

Memmott, J. 1999. The structure of a plant-pollinator food web. - Ecol. Lett. 2: 276-280.

Memmott, J. and Waser, N. M. 2002. Integration of alien plants into a native flower-pollinator visitation web. - Proc. R. Soc. B 269: 2395-2399.

Memmott, J., Waser, N. and Price, M. V. 2004. Tolerance of pollination networks to species extinctions. - Proc. R. Soc. B 271: 2605-2611.

Moldenke, A. R. 1975. Niche specialization and species diversity along an altitudinal transect in California. - Oecologia 21: 219-249.
Olesen, J. M. and Jordano, P. 2002. Geographic patterns in plant-pollinator mutualistic networks. - Ecology 83: 24162424.

Ollerton, J. and Cranmer, L. 2002. Latitudinal trends in plantpollinator interactions: are tropical plants more specialised? - Oikos 98: 340-350.

Petanidou, T. and Vokou, D. 1990. Pollination and pollen energetics in Mediterranean ecosystems. - Am. J. Bot. 77: 986-992.

Petanidou, T. and Ellis, W. N. 1993. Pollinating fauna of a phryganic ecosystem: composition and diversity. - Biodiv. Lett. 1: 9-22.

Petanidou, T. and Smets, E. 1995. The potential of marginal lands for bees and apiculture - nectar secretion in Mediterranean shrublands. - Apidologie 26: 39-52.

Petanidou, T. and Ellis, W. N. 1996. Interdependence of native bee faunas and floras in changing Mediterranean communities. - In: The conservation of bees. - The Linn. Soc. Lond. \& The Int. Bee Res. Ass, pp. 201-226.

Pleasants, J. M. 1981. Bumblebee response to variation in nectar availability. - Ecology 62: 1648-1661.

Possingham, H. P. 1992. Habitat selection by 2 species of nectarivore-habitat quality isolines. - Ecology 73: $1903-$ 1912.

Potts, S. G., Vulliamy, B., Dafni, A. et al. 2003. Linking bees and flowers: how do floral communities structure pollinator communities? - Ecology 84: 2628-2642.

Steffan-Dewenter, I. and Tscharntke, T. 1997. Early succession of butterfly and plant communities on set-aside fields. - Oecologia 109: 294-302.

Torres, C. and Galetto, L. 2002. Are nectar sugar composition and corolla tube length related to the diversity of insects that visit Asteraceae flowers? - Plant Biol. 4: 360-366.

Vazquez, D. P. 2005. Degree distribution in plant-animal mutualistic networks: forbidden links or random interactions? - Oikos 108: 421-426.

Vazquez, D. P. and Aizen, M. A. 2003. Null model analyses of specialization in plant-pollinator interactions. - Ecology 84: 2493-2501.

Warren, P. H. 1994. Making connections in food webs. - Trends Ecol. Evol. 9: 136-141.

Waser, N. M., Chittka, L., Price, M. V. et al. 1996. Generalization in pollination systems, and why it matters. - Ecology 77: 1043-1060.

Westerkamp, C. 1987. Das Pollensammelverhalten der sozialen Bienen in Bezug auf die Anpassungen der Blüten. Fachbereich Biologie. - Universität Mainz, p. 225. 
Appendix 1. Flower size parameters, flower abundance and number of visitors. Total number of open flowers in the 10 observation plots; mean (range) of flower size parameters (in $\mathrm{mm}$, based on 5 to 10 flowers); number of individuals, observed number of visitor species and potential number of species (first column is based on nectar holder depth constraint, second column is based on nectar holder depth and width constraint).

\begin{tabular}{|c|c|c|c|c|c|c|c|c|}
\hline \multirow{2}{*}{$\begin{array}{l}\text { Plant species } \\
\text { (plant family) }\end{array}$} & \multirow{2}{*}{$\begin{array}{l}\text { Number } \\
\text { of } \\
\text { flowers }\end{array}$} & \multirow{2}{*}{$\begin{array}{l}\text { Nectar } \\
\text { holder } \\
\text { depth }\end{array}$} & \multirow{2}{*}{$\begin{array}{c}\text { Nectar } \\
\text { holder width }\end{array}$} & \multirow{2}{*}{$\begin{array}{l}\text { Alighting } \\
\text { place length }\end{array}$} & \multirow{2}{*}{$\begin{array}{l}\text { Observed } \\
\text { individuals }\end{array}$} & \multirow{2}{*}{$\begin{array}{l}\text { Observed } \\
\text { species }\end{array}$} & \multicolumn{2}{|c|}{ Potential species } \\
\hline & & & & & & & depth & depth + width \\
\hline $\begin{array}{l}\text { Anacyclus valentinus } \\
\text { (Asteraceae) }\end{array}$ & 51005 & $\begin{array}{l}1.65 \\
(1.5-1.8)\end{array}$ & $\begin{array}{l}0.5 \\
(0.4-0.55)\end{array}$ & $\begin{array}{l}8.08 \\
(7-9.2)\end{array}$ & 41 & 19 & 78 & 78 \\
\hline $\begin{array}{l}\text { Anthyllis terniflora } \\
\text { (Fabaceae) }\end{array}$ & 12081 & $\begin{array}{l}4.2 \\
(3.9-4.4)\end{array}$ & $\begin{array}{l}0.2 \\
(0.15-0.25)\end{array}$ & $\begin{array}{l}4.9 \\
(4.5-5.2)\end{array}$ & 41 & 8 & 33 & 27 \\
\hline $\begin{array}{l}\text { Asphodelus fistulosus } \\
\text { (Liliaceae) }\end{array}$ & 3191 & $\begin{array}{l}2.16 \\
(1.6-2.45)\end{array}$ & $\begin{array}{l}0.33 \\
(0.25-0.4)\end{array}$ & $\begin{array}{l}9.4 \\
(8-10.25)\end{array}$ & 56 & 4 & 76 & 71 \\
\hline $\begin{array}{l}\text { Bituminaria bituminosa } \\
\text { (Fabaceae) }\end{array}$ & 1136 & $\begin{array}{l}6.36 \\
(5.9-6.8)\end{array}$ & $\begin{array}{l}0.45 \\
(0.4-0.5)\end{array}$ & $\begin{array}{l}4.42 \\
(4.2-4.6)\end{array}$ & 16 & 6 & 21 & 21 \\
\hline $\begin{array}{l}\text { Centaurea aspera } \\
\text { (Asteraceae) }\end{array}$ & 4602 & $\begin{array}{l}5.5 \\
(4.9-5.9)\end{array}$ & $\begin{array}{l}0.63 \\
(0.4-0.7)\end{array}$ & $\begin{array}{l}14.18 \\
(13.1-15.5)\end{array}$ & 32 & 8 & 28 & 28 \\
\hline $\begin{array}{l}\text { Convolvulus althaeoides } \\
\text { (Convolv.) }\end{array}$ & 514 & $\begin{array}{l}4.92 \\
(4.3-5.3)\end{array}$ & $\begin{array}{l}0.55 \\
(0.5-0.6)\end{array}$ & $\begin{array}{l}15.74 \\
(15.3-17)\end{array}$ & 24 & 5 & 32 & 32 \\
\hline $\begin{array}{l}\text { Coris monspeliensis } \\
\text { (Primulaceae) }\end{array}$ & 2404 & $\begin{array}{l}5.38 \\
(5.15-5.6)\end{array}$ & $\begin{array}{l}0.65 \\
(0.6-0.7)\end{array}$ & $\begin{array}{l}4.05 \\
(3.5-4.85)\end{array}$ & 23 & 6 & 27 & 27 \\
\hline $\begin{array}{l}\text { Diplotaxis erucoides } \\
\text { (Brassicaceae) }\end{array}$ & 10103 & $\begin{array}{l}2.66 \\
(1.5-3.3)\end{array}$ & $\begin{array}{l}0.29 \\
(0.25-0.35)\end{array}$ & $\begin{array}{l}5.56 \\
(5.4-6)\end{array}$ & 26 & 6 & 78 & 70 \\
\hline $\begin{array}{l}\text { Dorycnium pentaphyllum } \\
\text { (Fabaceae) }\end{array}$ & 50540 & $\begin{array}{l}2.24 \\
(2.1-2.5)\end{array}$ & $\begin{array}{l}0.4 \\
(0.3-0.5)\end{array}$ & $\begin{array}{l}3.22 \\
(2.6-3.6)\end{array}$ & 41 & 5 & 62 & 61 \\
\hline $\begin{array}{l}\text { Echium creticum } \\
\text { (Boraginaceae) }\end{array}$ & 4454 & $\begin{array}{l}6.1 \\
(5-6.6)\end{array}$ & $\begin{array}{l}0.9 \\
(0.85-0.95)\end{array}$ & $\begin{array}{l}12.9 \\
(12.1-15.5)\end{array}$ & 91 & 12 & 28 & 28 \\
\hline $\begin{array}{l}\text { Erodium malacoides } \\
\quad \text { (Geraniaceae) }\end{array}$ & 385 & $\begin{array}{l}0.19 \\
(0.1-0.25)\end{array}$ & $\begin{array}{l}0.18 \\
(0.15-0.2)\end{array}$ & $\begin{array}{l}4.51 \\
(3.4-5)\end{array}$ & 13 & 6 & 110 & 39 \\
\hline $\begin{array}{l}\text { Euphorbia serrata } \\
\text { (Euphorbiaceae) }\end{array}$ & 12781 & 0 & $\begin{array}{l}2.16 \\
(1.9-2.3)\end{array}$ & $\begin{array}{l}8.74 \\
(8.2-9.5)\end{array}$ & 71 & 23 & 111 & 111 \\
\hline $\begin{array}{l}\text { Euphorbia terracina } \\
\text { (Euphorbiaceae) }\end{array}$ & 23510 & 0 & $\begin{array}{l}1.34 \\
(1.3-1.4)\end{array}$ & $\begin{array}{l}3.14 \\
(2.5-3.5)\end{array}$ & 47 & 21 & 111 & 111 \\
\hline $\begin{array}{l}\text { Helichrysum stoechas } \\
\text { (Asteraceae) }\end{array}$ & 229840 & $\begin{array}{l}1.58 \\
(1.2-1.8)\end{array}$ & $\begin{array}{l}0.45 \\
(0.35-0.5)\end{array}$ & $\begin{array}{l}9.18 \\
(8.05-9.55)\end{array}$ & 88 & 29 & 88 & 86 \\
\hline $\begin{array}{l}\text { Linum suffruticosum } \\
\text { (Linaceae) }\end{array}$ & 1366 & $\begin{array}{l}2.12 \\
(1.8-2.3)\end{array}$ & $\begin{array}{l}0.2 \\
(0.15-0.25)\end{array}$ & $\begin{array}{l}13.16 \\
(10.8-16.3)\end{array}$ & 7 & 4 & 71 & 45 \\
\hline $\begin{array}{l}\text { Matthiola fruticulosa } \\
\text { (Brassicaceae) }\end{array}$ & 1720 & $\begin{array}{l}9.14 \\
(8.4-9.8)\end{array}$ & $\begin{array}{l}0.2 \\
(0.15-0.25)\end{array}$ & $\begin{array}{l}9.54 \\
(7.6-11)\end{array}$ & 1 & 1 & 7 & 6 \\
\hline $\begin{array}{l}\text { Moricandia arvensis } \\
\text { (Brassicaceae) }\end{array}$ & 3163 & $\begin{array}{l}9.54 \\
(8.9-10.9)\end{array}$ & $\begin{array}{l}0.34 \\
(0.3-0.4)\end{array}$ & $\begin{array}{l}10.42 \\
(9.5-12)\end{array}$ & 14 & 7 & 10 & 10 \\
\hline $\begin{array}{l}\text { Phagnalon saxatile } \\
\text { (Asteraceae) }\end{array}$ & 23026 & $\begin{array}{l}1.62 \\
(1.2-1.8)\end{array}$ & $\begin{array}{l}0.35 \\
(0.3-0.4)\end{array}$ & $\begin{array}{l}4.32 \\
(4.1-4.6)\end{array}$ & 38 & 9 & 88 & 81 \\
\hline $\begin{array}{l}\text { Reichardia tingitana } \\
\text { (Asteraceae) }\end{array}$ & 22717 & $\begin{array}{l}1.36 \\
(1.2-1.7)\end{array}$ & $\begin{array}{l}0.22 \\
(0.2-0.25)\end{array}$ & $\begin{array}{l}11.72 \\
(10.5-12.2)\end{array}$ & 23 & 9 & 88 & 57 \\
\hline $\begin{array}{l}\text { Rosmarinus officinalis } \\
\text { (Lamiaceae) }\end{array}$ & 1577 & $\begin{array}{l}5.21 \\
(4.6-6.2)\end{array}$ & $\begin{array}{l}0.55 \\
(0.45-0.7)\end{array}$ & $\begin{array}{l}7.1 \\
(6-8.3)\end{array}$ & 88 & 6 & 29 & 29 \\
\hline $\begin{array}{l}\text { Sideritis leucantha } \\
\text { (Lamiaceae) }\end{array}$ & 5720 & $\begin{array}{l}5.04 \\
(4.7-5.5)\end{array}$ & $\begin{array}{l}0.33 \\
(0.25-0.45)\end{array}$ & $\begin{array}{l}2.9 \\
(2.5-3.5)\end{array}$ & 11 & 5 & 29 & 29 \\
\hline $\begin{array}{l}\text { Sonchus tenerrimus } \\
\text { (Asteraceae) }\end{array}$ & 13027 & $\begin{array}{l}1.08 \\
(0.9-1.2)\end{array}$ & $\begin{array}{l}0.25 \\
(0.2-0.3)\end{array}$ & $\begin{array}{l}10.8 \\
(10.1-11)\end{array}$ & 35 & 10 & 94 & 74 \\
\hline $\begin{array}{l}\text { Teucrium murcicum } \\
\text { (Lamiaceae) }\end{array}$ & 17101 & $\begin{array}{l}3.36 \\
(2.7-3.9)\end{array}$ & $\begin{array}{l}0.49 \\
(0.4-0.55)\end{array}$ & $\begin{array}{l}4.44 \\
(3.7-5.4)\end{array}$ & 34 & 12 & 40 & 40 \\
\hline $\begin{array}{l}\text { Vella lucentina } \\
\text { (Brassicaceae) }\end{array}$ & 7324 & $\begin{array}{l}5.62 \\
(5.2-6.85)\end{array}$ & $\begin{array}{l}0.49 \\
(0.4-0.65)\end{array}$ & $\begin{array}{l}8.45 \\
(7.95-10.9)\end{array}$ & 34 & 8 & 27 & 27 \\
\hline $\begin{array}{l}\text { Vicia pseudocracca } \\
\text { (Fabaceae) }\end{array}$ & 462 & $\begin{array}{l}9.6 \\
(9.5-9.8)\end{array}$ & $\begin{array}{l}0.57 \\
(0.5-0.7)\end{array}$ & $\begin{array}{l}4.9 \\
(4.1-5.5)\end{array}$ & 2 & 2 & 7 & 7 \\
\hline
\end{tabular}

